\title{
ESTADO, PODER E CONFLITOS: ANÁLISE DO IMPACTO ESPACIAL DE ÁREAS PROTEGIDAS
}

\author{
Simone Fadel \\ Universidade do Estado do Rio Janeiro - UERJ \\ simonefadel@uerj.br \\ Felipe Rangel Tavares \\ Pontifícia Universidade Católica do Rio de Janeiro - PUC-RJ \\ feliperangel01@yahoo.com.br \\ Gabriel de Lima Souza \\ Universidade do Estado do Rio Janeiro - UERJ \\ gabriel.geo2010@gmail.com
}

\section{Resumo}

A instituição de áreas protegidas é uma política tradicional que vem sendo praticada e disseminada pelos governos modernos. No Brasil, o Código Florestal define as Áreas de Preservação Permanente, enquanto o Sistema Nacional de Unidades de Conservação - SNUC determina a criação, implantação e gestão das unidades. Percebemos que a criação de áreas protegidas pode acirrar conflitos já existentes, antes escamoteados por concepções de espaço neutro, vazio, que na verdade, surgem, com outros mecanismos, para promover a despolitização da questão ambiental no espaço. Este estudo analisa o impacto territorial (ação do Estado e conflitos) causado pelas políticas ambientais que criam áreas protegidas na Baixada Fluminense, no Rio de Janeiro. O espaço possui múltiplas dimensões, e o ordenamento espacial não pode ignorar essa constituição, em detrimento de determinados interesses, ideologias e intencionalidades.

Palavras chave: Espaço, Áreas protegidas, Conflitos.

\begin{abstract}
The establishment of protected areas is a traditional policy that has been practiced and disseminated by modern governments. In Brazil, the Forest Code defines the Permanent Preservation Areas, while the Sistema Nacional de Unidades de Conservação - SNUC determines the creation, deployment and management of stocks. We realized that the creation of protected areas can intensify existing conflicts before by-pass conceptions of neutral space, empty, in fact, arise, with other mechanisms to promote the un-politicization of environmental issues in space. This study analyzes the regional impact (state action and conflicts) caused by environmental policies that create protected areas in Baixada Fluminense, Rio de Janeiro. The space has multiple dimensions, and spatial planning can not ignore this constitution, to the detriment of certain interests, ideologies and intentions.
\end{abstract}

Keywords: Space, Protected areas, Conflict. 
A instituição de áreas protegidas é uma política tradicional, praticada e disseminada pelos governos modernos (Drummond, 1997). A história da política ambiental de preservação de áreas terrestres tem início no ano de 1872, nos Estados Unidos, com a criação do Parque Nacional de Yellowstone. Este modelo foi exportado para países da América Latina como Argentina (1903), Chile (1926) e Brasil (1937). Esta política expressa à intervenção do Estado na instituição legal de territórios especialmente protegidos, definindo critérios para a seleção das áreas e para o uso, estimulando, principalmente, o lazer, pesquisa e Educação Ambiental. Segundo Diegues (1996), a questão das áreas naturais protegidas gera inúmeros problemas de caráter político, social e econômico. Podemos perceber, de acordo com a corrente preservacionista, que o Parque é considerado um "espaço vazio", pois é extirpado seu conteúdo social, a população residente deve ser expulsa para que a "natureza e a vida selvagem" sejam contempladas. Essa concepção escamoteia a intencionalidade que o preenche de significados, valores e conflitos.

O Parque Nacional de Itatiaia foi o primeiro parque criado no Brasil, na década de 1930. A partir dele, ocorre a disseminação dessas áreas no território nacional e uma evolução legislativa, ainda mantendo a concepção da corrente preservacionista, que é o caso do Código Florestal de 1965, que institui as Áreas de Preservação Permanente (APP). Na década de 1990, o Brasil já contava com 34 parques. A partir do ano 2000, foi elaborado o Sistema Nacional de Unidades de Conservação (SNUC), que estabelece critérios e normas para a criação, implantação e gestão das Unidades de Conservação. As diretrizes do SNUC contemplam e asseguram a participação efetiva das populações locais, o que em outro momento, não era realizado, pois a gestão se apresentava mais centralizada e o homem era visto com visitante e não como morador. Os órgãos municipais e estaduais são considerados executores, com a função de implementar o SNUC, subsidiar as propostas de criação e administrar as Unidades de Conservação. Dessa forma, compreendemos que a criação de áreas protegidas permanece como a principal política ambiental brasileira, entretanto sua disseminação foi ampliada, uma vez que esferas de atuação de governo passam a ser locais.

Percebemos que há leis distintas para a proteção ambiental de áreas. O Código Florestal define as Áreas de Preservação Permanente, enquanto o SNUC determina a criação, implantação e gestão das unidades. Dentro da abordagem de cada lei observamos a representação de diferentes correntes (preservacionista e conservacionista), estabelecendo usos especificados. Segundo Diegues (1996), a essência da corrente Conservacionista é o uso adequado e criterioso dos recursos naturais, e opostamente a esta perspectiva, a essência da corrente Preservacionista pode ser descrita como a reverência à natureza no sentido de apreciação estética e espiritual da vida selvagem, protegendo-a contra o desenvolvimento moderno, industrial e urbano. A cada utilização do território e principalmente a partir da instituição de áreas protegidas refletindo uma corrente em específico, diferentes tipos de conflitos podem ser gerados e esperados. 
Com o propósito de promover maior justiça social e ambiental nós entendemos que se faz necessário trazer a tona e revelar esses processos que dão origem aos conflitos e os reproduzem no espaço, localizando, representando e difundindo o conhecimento produzido. A análise das áreas consideradas como Áreas de Preservação Permanente (APP) e as Unidades de Conservação permitiu observar em primeira instância que as diferentes correntes que fundamentam a criação de áreas protegidas, produzem diferentes conflitos relacionados aos tipos de uso.

Este estudo analisa o impacto territorial (ação do Estado e conflitos) causado pelas políticas ambientais que criam áreas protegidas na Baixada Fluminense, região composta por treze municípios que também fazem parte da região metropolitana do Rio de Janeiro. Durante os séculos passados diversas funções se desenvolveram na área, desde as atividades rurais como plantação de cana, café até a citricultura e posteriormente os loteamentos. Até o atual momento, a Baixada Fluminense, possui dezenove Unidades de Conservação (Parques, Reservas biológicas e APA), tendo em média uma Unidade de Conservação por município. A região apresenta áreas significativas de remanescentes do ecossistema manguezal, porém muito impactadas pela quantidade de lixo orgânico, esgoto e óleo proveniente de vazamentos constantes em pequenas quantidades ou abruptos em grande quantidade que são lançados na Baía diariamente, e transportados por rios e ação das marés.

Este trabalho está vinculado a uma pesquisa desenvolvida desde o ano de 2007 no Núcleo Interdisciplinar de Estudos do Espaço da Baixada Fluminense (NIESBF), grupo de pesquisa cadastrado no $\mathrm{CNPq}$, formado por docentes e discentes que têm como fim o estudo do espaço da Baixada Fluminense, onde se situa a Faculdade de Educação da Baixada Fluminense (FEBF), uma unidade da Universidade do Estado do Rio de Janeiro (UERJ).

Em 2011, nossa esteve pesquisa voltada a uma análise dos manguezais encontrados na região, em especial os encontrados no município de Magé, devido ao nível de degradação ao qual se encontram e por estarem presentes em áreas onde atuam projetos de reflorestamento, criação de áreas de proteção ambiental (APA) além de comunidades de pescadores que lutam por seus direitos e melhores condições de trabalho ${ }^{1}$.

Ao nos depararmos com esses aspectos socioambientais nas áreas do ecossistema manguezal, demos início a uma reflexão das problemáticas que num primeiro momento não foram tão explícitas para nós e que nos levaram a fazer a análise deste artigo. Perguntamo-nos como a criação de Unidades de Conservação tem sido refletida na dinâmica social e como tem se dado as relações de

${ }^{1}$ Esta etapa do trabalho foi apresentada no trabalho Caracterização das relações sócio-ambientais numa área de reflorestamento de manguezais no município de Magé - RJ, apresentado no V Seminário de Áreas Protegidas e Inclusão Social (V SAPIS), que ocorreu na Universidade Federal do Amazonas, em novembro de 2011 em Manaus, AM. 
poder entre o Estado, os grandes empreendimentos industriais e as próprias comunidades locais. Buscamos compreender de que forma as propostas de criação de áreas protegidas refletem na tensão entre atores sociais e se nesta perspectiva podemos elaborar então uma crítica ao modelo e como se tem dado o processo de instituição das Unidades de Conservação. Estariam elas atendendo aos conflitos como solução ou alternativa para amenizar ou evitá-los? Como a gestão dessas unidades procede nesta mediação de conflitos fundiários, políticos e ambientais? Será que realmente elas atendem a demanda a que se propõem?

Percebemos então que estão presentes na região analisada algumas relações socioambientais entre os atores sociais e as áreas protegidas. A primeira delas relaciona as Unidades de Conservação com grandes empreendimentos, como empresas privadas e indústrias que necessitam que seus empreendimentos perpassem por essas áreas. Uma segunda relação associa essas áreas aos movimentos sociais e aos moradores locais, vimos que tais áreas geram conflitos quando sua implantação e gestão não asseguram o bem estar das populações, como definido no Art. 15 do SNUC, uma vez que atores sociais hegemônicos (empresas e indústrias) possuem privilégios na implantação de seus empreendimentos, causando prejuízos para o meio ambiente e para a população local. Nós nos atemos também a discussão na qual percebemos essas relações socioambientais sob o viés de novas perspectivas quanto a gestão e união das Unidades de Conservação, o que tem surgido no Rio de Janeiro, com a criação do chamado Mosaico Norte Fluminense, que será melhor descrito ao longo deste artigo.

E por fim, observamos um quarto conflito observado nesta região, rica em áreas de preservação permanentes (APP) de manguezal, que diz respeito à contaminação do ecossistema por resíduos provenientes de atividades industriais, localizadas ao longo da bacia hidrográfica, transportados pelos rios ("valões") e depositados na Baía de Guanabara. Percebemos que a lei não contempla totalmente a dimensão de manter a natureza "intocada", uma vez que existe este impacto. Pareceunos essencial a elaboração deste estudo, pois ainda que o mesmo esteja localizado numa região do estado do Rio de Janeiro, ele reflete um problema enfrentado por outras nações que adotam esta política ambiental de proteção de áreas e que afeta diretamente o modo de vida de populações tradicionais (indígenas, ribeirinhos e pescadores), sendo de suma importância desvelar tais processos e intencionalidades que estão inseridos e implícitos na instituição dessas áreas.

A fim de responder as questões levantadas e para uma melhor compreensão da temática abordada, buscaremos explicar nossa discussão a partir da noção de tridimensionalidade do espaço, sugeridas por Ferreira (2011). Segundo o autor os atores sociais, a localidade em termos materiais e suas relações com o entorno, além do uso do espaço e a vida que se dá no lugar, são as três dimensões base para a compreensão do todo, ao que se diz respeito às tensões presentes no espaço. A partir dessa idéia e dos elementos os quais iremos abordar, dividimos o trabalho em quatro momentos que 
se complementam ao longo de nossa discussão: dedicamos o primeiro momento a uma caracterização da região da Baixada Fluminense e das áreas protegidas ali encontradas, seguido por uma análise das intencionalidades presentes pelos diferentes atores sociais que constituem esses espaços, partindo para uma abordagem mais localizada, porém de fundamental importância, pois se refere aos conflitos revelados nos diferentes processos de apropriação destes espaços pelos diferentes atores sociais envolvidos.

\section{Breve caracterização da Baixada Fluminense}

A Baixada Fluminense é uma região do estado do Rio de Janeiro composta por treze municípios (Duque de Caxias, Nova Iguaçu, São João de Meriti, Nilópolis, Belford Roxo, Queimados, Mesquita, Magé, Guapimirim, Japeri, Paracambi, Seropédica e Itaguaí) e que vêm sofrendo constantes transformações sociais, espaciais e econômicas, muitas delas caracterizadas por cada contexto e momento histórico pelos quais tem passado (Simões, 2007). Trata-se de uma área que compreende uma extensa planície flúvio-marinha rasa, que se desenvolve entre o sopé da Serra do Mar e o Oceano, interrompida por colinas e maciços costeiros, e cujo oito dos treze municípios compõem a Bacia Hidrográfica da Baía de Guanabara, compostas por cerca de 50 rios e riachos.

Segundo o Centro de Informações e Dados do Estado do Rio de Janeiro (CIDE-RJ) existe na área uma divisão regional de caráter histórico-cultural, baseado na história da conquista, na ocupação e evolução social e econômica. Os municípios componentes da Baixada Fluminense, fazem parte também da Região Metropolitana do Rio de Janeiro, o que favorece alguns municípios quanto às questões econômicas, tornando-os importantes centros de grandes industriais e empresas, Duque de Caxias, por exemplo, possui grande participação na economia do Estado do Rio de Janeiro. Esta contribuição provém principalmente pela presença, desde a década de 60, da Refinaria de Petróleo de Duque de Caxias (REDUC) no município.

Além da REDUC, a Baixada Fluminense poderá contar com investimentos advindos do Complexo Petroquímico do Rio de Janeiro (COMPERJ). O projeto foi lançado em 2007, junto ao Programa de Aceleração do Crescimento (PAC) pelo governo federal, com um investimento estimado de 8 bilhões de dólares. Apesar do empreendimento, um dos maiores do mundo no setor e o maior da história da Petrobrás, ter sua localização no município de Itaboraí, ele aponta para um maior desenvolvimento industrial na região da Baixada Fluminense, através do Arco Metropolitano ${ }^{2}$ (BR493) e do próprio Pólo Petroquímico já existente em Duque de Caxias, fazendo com os municípios da região sejam estrategicamente zonas de influência (Raulino, 2009).

À medida que observamos esses projetos industriais que visam o desenvolvimento econômico do

${ }^{2} \mathrm{O}$ Arco Metropolitano é um projeto que visa amenizar o tráfico de veículos na Região Metropolitana, a partir da construção de uma auto estrada, passando por municípios que compõem a Baixada Fluminense, entre outros. 
estado e das cidades envolvidas, não podemos deixar de refletir quanto as questões ambientais, também presentes e marcadas muita das vezes por injustiças ambientais. Estão concentradas na Baixada Fluminense, remanescentes de Mata Atlântica assim como as maiores faixas de remanescentes de manguezais da Região Sudeste, que segundo Pires (2010) encontram-se entre os municípios de Guapimirim, Magé, Itaboraí e São Gonçalo, os quais em 2010, 85\% representavam os preservados pela APA de Guapimirim. Nestes municípios, são encontradas as principais espécies de flora e fauna do mangue, porém, mesmo que este seja um ecossistema protegido pela legislação nacional como Área de Proteção Permanente (APP), é visível o aumento da degradação e poluição nos manguezais.

Os grandes empreendimentos e as indústrias atuam neste contexto como agentes de impactos, pois a poluição atmosférica e a contaminação química dos rios e da Baía de Guanabara, sem decorrentes dentre outros fatores, das atividades industriais. No ano 2000 mais de 1 milhão de litros de óleo vazaram de um dos dutos que interligam a REDUC ao terminal da Ilha d'Água, atingindo a Baía de Guanabara, o ecossistema manguezal e a atividade pesqueira na área (Acselrad e Mello, 2002). Este e outros exemplos da ação e poluição das atividades industriais são a causa de conflitos sociais que melhor serão descritos ao longo deste trabalho.

\section{Revelando intencionalidades}

De acordo com Lefebvre (1991), concebemos o espaço como um produto social, e conforme Santos (2006), como um conjunto indissociável, solidário e também contraditório, de sistema de objetos e sistema de ações. Qual a razão de utilizarmos estas concepções? O espaço contém e está contido nas relações de produção e nas forças produtivas. Por ser produzido socialmente, ele sustenta (é suporte), cria e transforma a sociedade que o produz. Portanto, o espaço se transforma à medida que a sociedade se transforma, tornando-se uma unidade, inseparáveis. O espaço é produto da ação de sociedades atuando ao longo da história, não sobre a materialidade, sobre objetos, mas, sobre si mesma. Ele (o espaço) é movimento, está em constante reformulação, reorganização, mudança, transformação.

Para Lefebvre, um espaço produzido se lê, implica um processo significante, está imbuído de intencionalidades, ou seja, cada porção do espaço possui uma informação, transmite mensagens, frações do social. Esta noção é abordada por Milton Santos, e, permite outra releitura crítica das relações entre objetos e ações. A ação, segundo Santos (2006), é um processo dotado de propósito. O homem pode ser definido por sua intencionalidade, por agir (in) conscientemente em direção dos objetos, imprimindo neles objetivos, projeções, desejos, significados, valores. De acordo com Lefebvre: 
Desde agora, assim como o espaço, a natureza encontra-se politizada, porque está inserida em estratégias conscientes ou inconscientes. O ordenamento de parques nacionais etc. já é uma estratégia, embora uma pequena estratégia, talvez uma tática. Mas seria preciso ver muito mais longe. (2008, p.67)

Para Lefebvre, o espaço é a objetivação do social (2008, p.44), não é ponto de partida, nem ponto de chegada, mas um intermediário, e enquanto mediação, "tal espaço instrumental permite tanto impor uma certa coesão (pela violência), quanto dissimular as contradições da realidade (sob uma aparente coerência racional e objetiva). O espaço, objetos e ações, é um projeto de vários atores, hegemônicos ou não, porém, um plano que nunca se realiza, não se conclui, sempre está sendo reescrito, a partir das práticas espaciais.

Se o espaço é caracterizado como vazio, isso não significa sua insignificância, pois, todo espaço é significativo e representa a intenção e os interesses de um grupo, mesmo aparentemente considerado vazio. Lefebvre enfatiza que o espaço é político e ideológico, e mesmo possuindo um aspecto neutro, vazio, indiferente em relação ao conteúdo, é porque ele já está ocupado, ordenado, já foi objeto de estratégias antigas, das quais nem sempre se encontram vestígios.

Se não há espaços realmente vazios, todo espaço é uma arena de intenções e interesses solidários e contraditórios, precisamos considerar que existem grupos mais ou menos fortes, cujo poder decisório é maior que o de outros grupos da sociedade, e estes definem, ordenam, a partir de seus objetivos, as relações sociais. Porém, o espaço não é um cárcere onde os “destituídos de poder" não têm escolhas, não têm voz. O espaço é também a resistência, a luta, a contestação e o protesto.

As áreas protegidas no Brasil são reguladas por duas legislações, o Código Florestal (Lei N 4.771, de 15 de setembro de 1965) e o Sistema Nacional de Unidades de Conservação - SNUC (Lei N ${ }^{\circ}$ 9.985, de 18 de julho de 2000). O Código Florestal estabelece definições, critérios e normas para assegurar a proteção de áreas cobertas ou não por vegetação nativa, com a função ambiental de preservar os recursos hídricos, a paisagem, a estabilidade geológica, a biodiversidade, o fluxo gênico de fauna e flora, proteger o solo e assegurar o bem estar das populações humanas. Esses elementos são definidos de acordo com o código como Área de Preservação Permanente - APP, cuja supressão total ou parcial de florestas somente pode ser realizada mediante autorização prévia do Poder Executivo Federal, quando necessária à execução de obras, planos e atividades ou projetos de utilidade pública ou interesse social, definidos como: atividades de segurança nacional e proteção sanitária; obras essenciais de infra-estrutura destinadas aos serviços públicos de transporte, saneamento e energia; e, demais obras, planos, atividades ou projetos previstos em resolução do Conselho Nacional de Meio Ambiente - CONAMA. As ações ou omissões contrárias às disposições 
do Código Florestal são consideradas de uso nocivo, e o mesmo define as contravenções penais puníveis com prisão simples e pagamento de multa para aqueles que o descumprirem.

Sobre as Unidades de Conservação, é importante ressaltar que, a primeira lei que tratou do assunto no Brasil, é a lei Federal no 6.902, de 1981. Os artigos $8^{\circ}$ e $9^{\circ}$ versam, respectivamente:

Art . $8^{\circ}$ - O Poder Executivo, quando houver relevante interesse público, poderá declarar determinadas áreas do Território Nacional como de interesse para a proteção ambiental, a fim de assegurar o bem-estar das populações humanas e conservar ou melhorar as condições ecológicas locais.

Art . $9^{\circ}$ - Em cada Área de Proteção Ambiental, dentro dos princípios constitucionais que regem o exercício do direito de propriedade, o Poder Executivo estabelecerá normas, limitando ou proibindo:

a) a implantação e o funcionamento de indústrias potencialmente poluidoras, capazes de afetar mananciais de água;

b) a realização de obras de terraplenagem e a abertura de canais, quando essas iniciativas importarem em sensível alteração das condições ecológicas locais;

c) o exercício de atividades capazes de provocar uma acelerada erosão das terras e/ou um acentuado assoreamento das coleções hídricas;

d) o exercício de atividades que ameacem extinguir na área protegida as espécies raras da biota regional.

Os objetivos do SNUC consistem na proteção de espécies ameaçadas de extinção, preservação e restauração da diversidade de ecossistemas, proteção de paisagens e recursos hídricos, e dentre outros, a proteção dos recursos naturais necessários à subsistência de populações tradicionais, respeitando e valorizando seu conhecimento e sua cultura e promovendo-as socialmente e economicamente. Esta perspectiva não é contemplada no Código Florestal, que apresenta em sua constituição, a influência da corrente Preservacionista, onde o homem não é morador, apenas um visitante, ou seja, ele não pode ocupar ou utilizar as áreas definidas como APP. O SNUC busca o envolvimento da sociedade no estabelecimento da política de unidades de conservação, tal como, a participação da população local na criação e administração das áreas protegidas. Às populações tradicionais deve estar assegurado os meios de subsistência ou justa indenização pelos recursos perdidos. Cada unidade de conservação está inserida numa categoria, que se dividem em dois grupos: Unidades de Proteção Integral e Unidades de Uso Sustentável. Para a proteção integral, o objetivo básico é preservar a natureza, admitindo apenas o uso indireto, livres de alterações causadas por interferência humana, que não envolve o consumo, coleta, dano ou destruição dos recursos naturais. O objetivo básico das unidades de uso sustentável é compatibilizar a conservação da natureza com o uso sustentável, ou seja, exploração do ambiente de forma socialmente justa e economicamente viável, de maneira a garantir perenidade dos recursos naturais, mantendo a 
biodiversidade e demais atributos ecológicos, segundo o SNUC. A criação de uma unidade de conservação deve ser precedida por estudos técnicos e de consulta pública, deve possuir um Plano de Manejo, que é um documento técnico que, de acordo com os objetivos gerais da unidade de conservação, estabelece o seu zoneamento e as normas que devem presidir o uso da área. Os órgãos executores são o Instituto Brasileiro do Meio Ambiente e dos Recursos Naturais Renováveis Ibama e o Instituto Chico Mendes. Em caráter supletivo, os órgãos estaduais e municipais cuja função é de implementar o SNUC, subsidiar propostas de criação e administrar as unidades de conservação. Para finalizarmos nossas considerações sobre o SNUC, queremos destacar o art.32, que aborda a articulação do conhecimento científico com o saber das populações tradicionais:

Os órgãos executores articular-se-ão com a comunidade científica com o propósito de incentivar o desenvolvimento de pesquisas sobre a fauna, a flora e a ecologia das unidades de conservação e sobre formas de uso sustentável dos recursos naturais, valorizando-se o conhecimento das populações tradicionais. (Sistema Nacional de Unidades de Conservação, 2000)

Diferentemente das Áreas de Preservação Permanente, definidas pelo Código Florestal, as Unidades de Conservação regidas pelo SNUC, representam uma ampliação da política pública de áreas protegidas, cuja criação, gestão, administração estão mais acessíveis às esferas locais, incluindo as populações tradicionais, moradores, que, principalmente nas unidades de uso sustentável, podem ser as responsáveis pela coordenação e manutenção da área. Para cada categoria de unidade haverá a definição de limites de uso, e o Plano de Manejo é o documento que dá as diretrizes para utilização da área.

Desta forma, buscaremos entender o quadro atual das Unidades de Conservação da Baixada Fluminense atentando, sempre que possível analisar, ou mesmo apenas pontuar, os conflitos e a regulação dos mesmos nas diferentes práticas sociais que se desenvolvem nestes espaços, não destituindo as questões e intencionalidades postas neles.

Atualmente a Região da Baixada Fluminense possui um total de dezenove Unidades de Conservação, que envolvem desde Parques Nacionais, Municipais, Estaduais até Áreas de Proteção Ambiental e Estações Ecológicas3. Apesar de algumas delas serem pouco conhecidas, essas UCs abrigam cerca de $740 \mathrm{~km}^{2}$ de Mata Atlântica (Curvello e Latini, 2007) e os remanescentes do ecossistema manguezais. Muitas dessas unidades seguem o artigo 27 do Sistema Nacional de Unidades de Conservação (SNUC) quanto à elaboração de um Plano de Manejo, os quais nos fornecem suas características naturais além do seu sistema de gestão. Dentre as dezenove unidades que compreendem os municípios da Baixada, podemos destacar aquelas de grandes extensões como

\footnotetext{
${ }^{3}$ As Unidades de Conservação que tem suas áreas em municípios que compõem a Baixada Fluminense são: O Parque Nacional da Serra dos Órgãos, Parque Estadual dos Três Picos, os Parques Municipais da Taquara, de Nova Iguaçu e de Curió, a Flora Mário Xavier, as Reservas Biológicas do Tinguá e Araras Estações Ecológicas da Guanabara e Paraíso e as APAs Petrópolis, Guapimirim, Floresta do Jacarandá, Rio dos Frades Gericinó/Mendanha, da Bacia de Guandu, Caixa D'Água, Estrela e Suruí.
} 
o Parque Nacional da Serra dos Órgãos, o Parque Nacional de Nova Iguaçu, o Parque Estadual dos Três Picos e a APA de Guapimirim até áreas menores como a APA Estrela, a REBIO de Tinguá, e a APA Suruí.

O Parque Nacional da Serra dos Órgãos, criado na década de 40, abrange trechos de quatro municípios do Estado do Rio de Janeiro, dois deles da Região Serrana (Petrópolis e Teresópolis) e os outros da Baixada Fluminense (Magé e Guapimirim). É famoso por apresentar um conjunto de encostas íngremes, muito acidentadas, florestadas, paredões verticais e os famosos picos, dez picos com mais de $2.000 \mathrm{~m}$ e outros seis com mais de $1.500 \mathrm{~m}$, dentre os quais podemos destacar o famoso Dedo de Deus, com 1692 metros de altura e que representa o montanhismo brasileiro e fluminense e a Pedra do Sino, com 2.263m, sendo o ponto mais culminante do Parque. Abrangendo municípios da Baixada Fluminense e da Região Serrana encontra-se também APA Petrópolis, a primeira APA criada no Brasil em 1982, apesar de ser delimitada apenas em 1992, seguida pela APA de Guapimirim criada em 1984 e localizada ao fundo da Baía de Guanabara. A APA de Guapimirim destina-se principalmente a proteção de manguezais e a permanência de populações locais que de alguma forma possui uma relação com o ambiente. Nos domínios da APA, há uma área que apresenta características ecológicas e biológicas próximas ao do período de pré-colonização do país, área esta que deu origem a Estação Ecológica da Guanabara.

Em 1992, foi criado ainda o Parque Natural Municipal da Taquara (PNMT), reserva de proteção integral de Mata Atlântica localizada em Duque de Caxias, a qual também já foi registrada a presença de mico-leão-dourado e que forma um corredor ecológico juntamente com a APA Petrópolis e a REBIO do Tinguá, localizada entre os municípios de Nova Iguaçu, Duque de Caxias, Miguel Pereira e Petrópolis, foi criada em 1989 e hoje é uma das maiores reservas de Mata Atlântica do Estado do Rio de Janeiro. Também em Nova Iguaçu, foi criado em 1998, o Parque Municipal de Nova Iguaçu, com o intuito de proteger flora e fauna e permitir uma opção de lazer para a população local.

De acordo com o artigo 26 do SNUC, quando um conjunto de unidades e conservação de categorias diferentes ou não, próximas, justapostas ou sobrepostas, e outras áreas protegidas públicas ou privadas, elas irão constituir-se num mosaico o qual a gestão deverá ser realizada de forma integrada. O Ministério do Meio Ambiente reconhece um total de seis mosaicos, dentre os quais podemos destacar o chamado Mosaico Central Fluminense, Criado pela Portaria 350/2006, do Ministério do Meio Ambiente e que abrande 22 Unidades de Conservação, incluindo as que possuem seus limites na Baixada Fluminense. O Mosaico tem aproximadamente 220.000 hectares que incluem campos de altitude, mata atlântica montana e de baixada, manguezais e mar (Herrera, 2010).

\section{Revelando Conflitos}


A diversidade de Unidades de Conservação presentes na Baixada Fluminense é notória. Não só nos diferentes biomas que se constituem objeto de guarda pelo Estado, como pela instância estatal que define as regras de uso (Federal, Estadual ou Municipal). Da mesma forma, os tipos de unidades vão variar desde Reserva Biológica de uso extremamente restrito, com ocorre com a Reserva Biológica de Tinguá. Até as unidades constituídas pela denominação de parques municipais que pressupõem a participação, mesmo que regulada, da população local.

No escopo deste trabalho não foi possível apreender a diversidade dos conflitos existentes em cada uma destas unidades, não era nosso objetivo traçar um perfil antropológico das diferentes comunidades existentes no entorno de cada uma destas unidades (Fadel, 2006). No entanto, podemos afirmar que tanto o uso restrito imposto ao espaço de Tinguá é constantemente colocado em questão seja pela apropriação de espaços do entorno da reserva para fins de lazer da comunidade, como banho de cachoeiras ou piscinas naturais. Ou como práticas consideradas, de fato ilegais, como a caça de animais silvestres. Com relação às unidades de gestão municipal temos os Parques municipais já citados com permissão de visitação regulada ou projetos de educação ambiental de cunho profundamente conservador. No entanto, estes Parques delimitam áreas verdes, caracterizadas por resquícios de mata atlântica em meio à mata secundária.

Outras unidades, no entanto, não delimitam nenhuma área de real interesse ambiental e sua criação exige um estudo profundo sobre a atual estrutura fundiária da região. Afinal, qual o propósito de se delimitar áreas para a preservação ambiental se as mesmas estão destituídas de um ambiente a ser preservado? Em que medida estas áreas serviriam como recurso para valorização das áreas do seu entorno e para futuros empreendimentos imobiliários? Estas questões, embora não respondidas no âmbito deste trabalho, precisam ser colocadas no campo de análise dos espaços "preservados da região".

Herrera (2010) aponta para o fenômeno de prostituição ambiental na criação de unidades de conservação.

No caso estudado, pode-se tomar como exemplo a criação da APA municipal de Suruí, em Magé, motivada explicitamente pela secretaria de meio ambiente municipal para recolher benefícios de compensação do COMPERJ. Ou seja, subverte-se a lógica da criação das UCs que, em vez de indicar preocupação pública na proteção ambiental, vincula-se à aprovação política de atividades poluidoras esperando-se os recursos financeiros da compensação. (Herrera, 2010, p.44)

A prática da "política estatal de prostituição ambiental" não impõe apenas sacrifícios ambientais, mas corrobora com práticas de efetiva destruição de práticas tradicionais de pesca desenvolvidas nas regiões que apresentam o ecossistema manguezal. Este conflito revelado pela atuação e organização dos pescadores artesanais, através da AHOMAR, pode ser tomado aqui como exemplo de conflitos na região. Não só pela sua importância no âmbito ambiental, pois é consensual a 
importância da preservação dos manguezais do fundo da Baía de Guanabara para a dinâmica hídrica da mesma (Amador, 1997), como pelas possibilidades de se perceber diferentes formas de atuação dos atores sociais e suas respectivas intencionalidades na constituição de uma Unidade de Conservação.

Conforme indicado anteriormente, a empresa Petrobras está presente na região seja através de sua Refinaria - REDUC, e agora através da construção do Pólo Petroquímico denominado COMPERJ. No entanto, a forma institucionalizada não é suficiente para que se tenha noção do impacto que a Petrobrás vem infringindo ao ambiente e populações locais. Segundo a empresa, o vazamento ocorrido em 2000, aconteceu por um erro numa das válvulas de um de seus dutos. Já para os pescadores, o acidente faria parte de uma estratégia da empresa para desapropriar os mesmos de seu espaço de vida e trabalho. Segundo o atual líder e representante da AHOMAR, Alexandre Anderson de Souza, em entrevista concedida à equipe da BV no dia 14 de março de 2012:

Hoje no Brasil a legislação está criando precedentes do judiciário e os governos estão criando precedentes para a industrialização do Brasil, o crescimento. A ordem de progresso a qualquer custo. O único entrave que tem na Baía de Guanabara legal é o social, é a questão dos usuários da água, dos pescadores da baía de Guanabara. São os pescadores as comunidades que vivem economicamente na região. Você causando um acidente, você cria além da mortandade, você cria um desânimo e você cria uma poluição constante e também uma eminência de outros vazamentos que vão causar o que? Uma retirada, um êxito dos pescadores locais. Nenhum pescador quer construir uma casa ou comprar um segundo barco para operar numa mesma região que tem o risco de ter outros vazamentos. O vazamento criou ali um precedente da Petrobrás em dizer que aquela região já está contaminada. Então toda vez que nós chegamos a justiça, ela diz que a região já está contaminada, que não há pescado por causa do óleo de 2000, mas também pelos futuros vazamentos que podem ocorrer. (...)Então ali se tornou uma área morta. Toda área do entorno ou próximo a REDUC é uma área morta devido ao vazamento de 2000. Então quer dizer que se criou ali um estigma por aquele local, pelo o uso da pesca. É um peixe hoje, que tendo um gosto ou não, o pessoal considera um peixe contaminado. $O$ peixe da região que é pescado próximo a REDUC, é um peixe que tem pouco valor agregado. Os grandes comerciantes, a própria população evitam comer o peixe da região da REDUC, por achar que está contaminado, muitas vezes já sabendo que está e também porque tem gosto de óleo. Aí os pescadores em sua sabedoria Caiçara acreditam que isso foi proposital.

Face ao poder da Petrobrás, tanto pescadores quanto órgãos de gestores das unidades são marginalizados, isto é, seus discursos são destituídos de poder.

Nas instâncias burocráticas de poder a prática de destituição do cargo de chefia de funcionários que se contrapõem a imposição é a norma. O gestor da APA de Guapimirim, ao se confrontar diretamente com os interesses da Petrobrás foi ameaçado de ser destituído do cargo pela Ministra do 
Meio Ambiente. Isto ocorre quando confluem os interesses dos gestores ambientais e a comunidade do entorno, neste caso, pescadores. O trecho a seguir, foi divulgado pela AHOMAR, através da internet, e apresenta o posicionamento dos pescadores contra a retirada do gestor da área de conservação:

\author{
Prezados "Amigos e Conselheiros"
}

Já de ante mão estendemos nossa solidariedade a esses excelentes técnicos e ambientalistas, em especial ao amigo "Breno Herrera".

Digo que foi com grande indignação e revolta que nós comunidades e pescadores artesanais da Baía de Guanabara recebem essa notícia; da possibilidade da saída desta direção, na administração da APA Guapimirim; que tanto fez pela preservação e proteção do ecossistema marinho da Baía de Guanabara.

Hoje milhares de famílias são beneficiadas e podem utilizar de forma sustentável e consciente os recursos naturais ainda bem preservados em nossa região, isso graças aos esforços e o trabalho dos administradores e conselheiros da "APA de Guapimirim" e "ESEC Guanabara", através de uma gestão participativa com as comunidades ao redor.

Nós pescadores e lideranças externamos nosso apoio para qualquer ação em prol de se reverter este quadro e desde já articulamos um grande movimento de repúdio a mais essa tentativa de eliminar e afastar as pessoas do "bem", da luta ambiental e social deste país.

Estaremos presentes há convocatória ; e desde já divulgaremos a todos no "Brasil" e no "Exterior", a mais essa lamentável tentativa de nos tirar o direito de ter um "meio ambiente limpo e equilibrado para nossa e as futuras gerações" ! (Alexandre Anderson, abril, 2012)

Percebe-se neste trecho, pra além do repúdio a ação, uma articulação entre o ambiental (aquilo posto como natureza a ser preservada) e a atividade laboral da pesca artesanal. O entendimento de que estas duas perspectivas ou intencionalidades sobre o espaço em questão não são conflituosas, ao contrário, é motivo de unificação "da luta ambiental e social deste país". A luta de populações tradicionais, de pescadores artesanais em conjunto com gestões comprometidas com a administração eficiente e justa de áreas protegidas é uma expressão das práticas espaciais, em situação de conflito, de uma sociedade que demonstra resistência frente aos interesses (de empresas, indústrias, do próprio Estado) que escapam da esfera local, mas interferem de forma agressiva no lugar, deteriorando não só o meio ambiente, mas o modo de vida, o cotidiano. Qual será o destino dessas populações se a espoliação não só destruir suas raízes com o lugar, como também, for capaz de enterrar suas tradições?

Neste sentido, percebemos que a criação de áreas protegidas pode acirrar conflitos já existentes, antes escamoteados por concepções de espaço neutro, vazio, que na verdade, surgem, com outros mecanismos, para promover a despolitização da questão ambiental no espaço. As áreas protegidas, embora possam estar desocupadas, são objetos, portanto, não são espaços vazios. Muitas ações se praticam em relação a este objeto, revelando as diversas intencionalidades conflituosas que incidem sobre ele. A resolução de problemas ambientais com o uso de técnicas ditas eficientes, o discurso do desenvolvimento sustentável, programas de despoluição, reciclagem, compensação ambiental, recuperação de áreas degradadas são os artifícios utilizados para amenizar o impacto de grandes empreendimentos. São ações que partem de um grupo com determinados interesses, cujo espaço é 
apenas meio para reprodução das relações de produção capitalistas, conseqüentemente, da condição desigual. Onde está a sociedade? Ela participa (estimulada a ser complacente e passiva) de audiências públicas, para tentar compreender os impactos dos empreendimentos e as soluções técnicas que serão executadas para garantir o seu bem-estar e influenciarão permanentemente sobre o seu cotidiano.

Revela-se então uma contradição: o Estado, supremo legislador, executor, fiscalizador, planejador é aquele que pode decretar a criação de áreas protegidas, para a preservação de atributos naturais, bem-estar da sociedade. Ele é o mesmo que pode atuar no enfraquecimento dessas gestões, quando outros interesses surgirem. Ele atuará com outros propósitos, com a finalidade de privilegiar atores hegemônicos. Dessa forma, buscam-se maneiras de promover a proteção, com o menor impacto possível (recuperação, compensação, replantio). Entretanto, nesse processo, as práticas espaciais das populações são totalmente ignoradas, e tantos mecanismos quanto forem necessários, serão utilizados para romper a resistência. O espaço é produzido mediante os conflitos, à colisão de interesses, estratégias, intencionalidades. Não podemos esquecer que ele nunca é neutro, vazio, antes, é instrumento nas mãos de alguém.

\section{Áreas protegidas para quem?}

Ainda que a criação e gestão de áreas protegidas tenha se ampliado à esfera local, assegurando o envolvimento e a participação da sociedade, as lutas por justiça social e ambiental permanecem mediante inúmeros conflitos. A participação popular é assegurada, mas até que ponto suas decisões são respeitadas? Seus saberes não são sufocados pela cientificidade, pelo conhecimento técnico, pela oportunidade de lucrar, de movimentar a economia? Por determinados interesses políticos?

As áreas protegidas, delimitadas, criadas e administradas, são um modelo de ordenamento espacial, uma estratégia legal para a conservação dos atributos bióticos e abióticos. Esse ordenamento deve, primeiramente, considerar o espaço e o tempo, como fatores essenciais na produção das relações sociais. As ações, os objetos, todos possuem um conteúdo, são politizados, sua existência material é produto das relações sociais, que são resultado da materialidade existente. Assim, o tempo, o cotidiano, o modo de vida, não homogêneos, precisam ser respeitados, tal como, as tradições, costumes, símbolos e práticas espaciais pertencentes ao lugar.

As dádivas da natureza (manguezais, rios, solo), que são utilizados pelos homens, tornam-se objetos, a partir de um conjunto de interações sociais (Santos, 2006). Esses atributos são parte de um conjunto significante para uma população que historicamente se relacionou não apenas economicamente, no sentido de valor de troca dos recursos naturais, mas simbolicamente, como 
valor de uso, uma vez que diversas emoções, lembranças, vivências e experiências são marcas imateriais dessas sociedades no lugar.

O espaço possui múltiplas dimensões, e o ordenamento espacial não pode ignorar essa constituição, em detrimento de determinados interesses, ideologias e intencionalidades. As áreas protegidas são um produto social, dotados de propósitos, cuja maior finalidade precisa ser a resolução de incoerências no uso, em íntima harmonia com a promoção de justiça ambiental, indissociavelmente, de justiça social, protegendo não apenas atributos bióticos e abióticos, como também, pessoas, tradições, costumes, saberes, um cotidiano específico que se realiza dentre outras práticas espaciais.

\section{Referências:}

ACSELRAD, Henri. e MELLO, C. C. A. Conflito Social e risco ambiental - o caso do vazamento do óleo na Baía de Guanabara. In: H. ALIMONDA. (Org.). Ecologia Política - Naturaleza, Sociedad y Utopia. Buenos Aires, 2002.

AMADOR, Elmo da Silva. Baía de Guanabara e Ecossistemas Periféricos: Homem e Natureza. Rio de Janeiro: E.S. Amador, 1997. 539p.

CURVELLO, Tânia. da Cunha Vieira e LATINI, Rose Mary. Unidades de Conservação da Baixada Fluminense. In: Revista Pilares da História Duque de Caxias e Baixada Fluminense. ano 6, número 7 / Instituto Histórico Vereador Thomé Siqueira Barreto / Câmara Municipal de Duque de Caxias e Associação dos Amigos do Instituto Histórico - Rio de Janeiro, 2007.

DIEGUES, Antônio Carlos Moraes. O mito moderno da natureza intocada. São Paulo, Hucitec, 1996. 161p.

DRUMMOND, José Augusto. Devastação e Preservação Ambiental: os parques nacionais do Estado do Rio de Janeiro. Niterói, EdUFF, 1997. 159p.

FADEL, Simone. Representações sobre o meio ambiente em Nova Divinéia. Dissertação de mestrado, PUC-Rio, 1992.

FERREIRA, Álvaro. A Cidade do século XXI: segregação e banalização do espaço. Rio de Janeiro: Consequência, 2011.296p.

HERRERA, Breno. Vetores de Desenvolvimento Industrial em Áreas Protegidas: A Relação do Mosaico Central Fluminense com o Complexo Petroquímico do Rio de Janeiro. In: Anais do II Seminário de Pesquisa e Iniciação Científica do Instituto Chico Mendes de Conservação da Biodiversidade: biodiversidade e economia / Afonso Henrique Leal, Ivan Salzo, Katia Torres Ribeiro (orgs.). Brasília: Instituto Chico Mendes de Conservação da Biodiversidade - ICMBio, 2010.

LEFEBVRE, Henri. The Production of Space. Blackwell Publishing, 1991. 434p. Espaço e política. Belo Horizonte, Editora UFMG, 2008. 192p. 
PIRES, Ivan de Oliveira. Manguezais da Região do recôncavo da Baía de Guanabara: revista através dos mapas. In: Revista da Gestão Costeira Integrada. Portugal, 2010.

RAULINO, Sebastião. Construções sociais da vizinhança: temor e consentimento nas representações dos efeitos de proximidade entre grandes empreendimentos industriais e populações residentes. Tese (doutorado) - Universidade Federal do Rio de Janeiro, Instituto de Pesquisa e Planejamento Urbano e Regional, 2009.

SANTOS, Milton. A Natureza do Espaço: Técnica e Tempo, Razão e Emoção. 4. Ed. São Paulo: Editora da Universidade de São Paulo, 2006. 259p.

SIMÕES, Manoel Ricardo. A cidade estilhaçada: reestruturação econômica e emancipações municipais na Baixada Fluminense. Rio de Janeiro, Entorno, 2007. 300p.

SNUC. Sistema Nacional de Unidades de Conservação, 2000.

UNIDADE GESTORA DO PARQUE NACIONAL DA SERRA DOS ÓRGÃOS. Plano de Manejo do Parque Nacional da Serra dos Órgãos. 2007. http://www.ibama.gov.br/parnaso[Março de 2012]. 